\title{
Experiments and Modeling of Unprotected Structural Steel Elements Exposed to a Fire
}

\author{
ANTHONY HAMINS, KEVIN MCGRATTAN, KULDEEP PRASAD, \\ ALEXANDER MARANGHIDES, and THERESE MCALLISTER \\ Building and Fire Research Laboratory \\ National Institute of Standards and Technology \\ 100 Bureau Drive, Stop 8663 \\ Gaithersburg, MD 20899-8663 USA
}

\begin{abstract}
A large-scale fire experiment was conducted to assess the accuracy of a combination of gas and solid-phase models designed to predict the temperatures of structural steel elements exposed to a fire. The experiment involved a 2 MW heptane spray fire in a compartment that was nominally $4 \mathrm{~m}$ by $7 \mathrm{~m}$ by $4 \mathrm{~m}$ tall. The compartment openings were designed such that natural ventilation flowed into the compartment from one side and flowed out through the opposing side. Measurements included the surface temperature of uninsulated steel elements and the temperature of the upper layer gases in the compartment. The measurements were compared to predictions made by a computational fluid dynamics model of the fire coupled with a finite-element model of the steel. The numerical predictions of the steel surface temperatures were within $8 \%$ of the measurements on-average. An analysis showed that the uncertainty in the prediction could be attributed to the uncertainty in the prescribed heat release rate in the fire model.
\end{abstract}

KEYWORDS: CFD, compartment fires, performance-based design, structural response

\section{INTRODUCTION}

This paper describes a relatively simple large-scale fire experiment that was conducted to test the accuracy of a coupled computational fluid dynamics (CFD) model of fire-driven flow and a finite-element thermal model of exposed structural steel elements. The calculation procedure is challenging in large, geometrically complex buildings due to the disparity in length and time scales between the models. Typical length scales range from tens of meters, characteristic of several floors within a building, to a few centimeters, characteristic of structural components and fire-resistant insulation. Typical time scales range from hundredths of a second to hours, depending on the type of CFD model and the duration of the fire. To simulate the long burn times in large spaces, the CFD model must sacrifice spatial resolution. Given the performance of current generation computers, CFD simulations of a building fire can only resolve details of the flow field down to several tens of centimeters. Thus, there is a gap of at least an order of magnitude in spatial resolution between the gas-phase and solid-phase models.

Much of the previous work on the thermal behavior of steel subjected to a fire has focused on developing time-temperature curves for building elements as a function of fire load and ventilation conditions [1]. Other work has considered the thermal behavior of structural steel elements experiencing uniform heating, such as in a furnace. There has also been some research on the heating of structural steel elements by a localized fire. Pchelintsev et al. [2] investigated the case of a steel beam installed beneath a ceiling and exposed to fires of varying sizes. Applying a correlation for the radial heat flux 
distribution from the literature, a finite-element code was shown to accurately simulate the local temperature behavior of the steel beam. In many fire scenarios, however, a fire is not due to a single source, nor is it necessarily stationary. In this study a fire model, rather than a correlation, is used to determine the thermal boundary conditions on the structural elements. Such an approach allows consideration of many types of fire scenarios, as well as the thermal behavior of complex three-dimensional multi-element structures, which facilitates performance-based design solutions for the behavior of structures under actual fire conditions.

\section{OVERVIEW OF EXPERIMENTS}

A series of fire experiments was conducted to assess the accuracy of a methodology combining gas and solid-phase models designed to simulate the thermal behavior of structural steel elements exposed to a fire in a compartment. Within a steel-frame compartment ( $3.68 \mathrm{~m}$ wide, $7.04 \mathrm{~m}$ long, and $3.82 \mathrm{~m}$ high) lined with calcium silicate board were placed several unloaded, uninsulated steel components. Figure 1 shows a plan view of the compartment. A vertical baffle $1.00 \mathrm{~m}$ high, $2.05 \mathrm{~m}$ wide, and $0.15 \mathrm{~m}$ deep was placed $2 \mathrm{~m}$ from the west wall of the compartment. The placement and dimensions were selected to limit flame tilt and prevent flames from extending through the compartment openings. Ventilation in the compartment was induced by the fire. There was no forced ventilation. The compartment was equipped with eight openings, four inlets near the floor on the west wall, and four outlets at a higher vertical location on the east wall. The four inlets were $0.3 \mathrm{~m}$ above the floor, $0.6 \mathrm{~m}$ wide and $0.7 \mathrm{~m}$ high. The four outlets were $1 \mathrm{~m}$ below the ceiling and of similar dimension to the inlets.

The fire source was a liquid hydrocarbon fuel, which was delivered via two nozzles spraying downwards onto a $1 \mathrm{~m}$ by $2 \mathrm{~m}$ pan. The fuel was delivered in a steady manner for 14 min $20 \mathrm{~s}(860 \mathrm{~s})$. The fuel was a commercial blend of heptane isomers with a heat of combustion and carbon to hydrogen ratio within $1 \%$ (mass fraction) of the value for $n$ heptane. The yields of soot $(0.0149 \pm 0.0033)$, $\mathrm{CO}(<0.008)$, and $\mathrm{CO}_{2}(3.03 \pm 0.12)$, which are input parameters required by the fire model, were measured in the spray fire burning in the open [3]. Unless otherwise noted, all uncertainties in this paper are expressed as the combined expanded uncertainty, which represents two times the standard deviation.

In the experiment, the fuel flow was rapidly ramped-up in less than $5 \mathrm{~s}$ to a steady rate of $3.80 \mathrm{~L} / \mathrm{min} \pm 0.04 \mathrm{~L} / \mathrm{min}$. The heat release rate, based on the fuel flow rate and the heat of combustion, was estimated as $1960 \mathrm{~kW}$. This estimate assumed that the combustion efficiency was 1 , characteristic of a free-burning heptane spray fire [3]. Since the combustion efficiency may be less for a fire burning in a compartment, the heat release rate of the fire was measured using conventional oxygen consumption calorimetry in the exhaust stream, which flowed through a $6 \mathrm{~m}$ by $6 \mathrm{~m}$ hood. The heat release rate, based on calorimetry, was measured as $1970 \mathrm{~kW} \pm 11 \%$, which was in agreement with the estimate from the measured fuel flow. Bryant et al. [4] give a detailed description of the calorimetry facility, the experimental methodology, instrumentation, calibration, and measurement uncertainty.

Type $\mathrm{K}$ thermocouples were spot-welded onto the surface of the steel components at multiple locations to measure the local time-varying surface temperatures. The gas temperature was measured at two locations in the compartment, one on the inlet side and one on the outlet side, using six aspirated thermocouples, three at each location shown in 
the figure (TAE and TAW). The aspirated thermocouples were located $53 \mathrm{~cm}$ from the north wall and $1 \mathrm{~m}$ from the east and west walls of the compartment at three vertical heights, namely $35 \mathrm{~cm}, 215 \mathrm{~cm}$, and $365 \mathrm{~cm}$ above the floor (or $348 \mathrm{~cm}, 167 \mathrm{~cm}$, and $17 \mathrm{~cm}$ below the ceiling). Uncertainties in the aspirated thermocouple measurement were estimated as $7^{\circ} \mathrm{C}$.

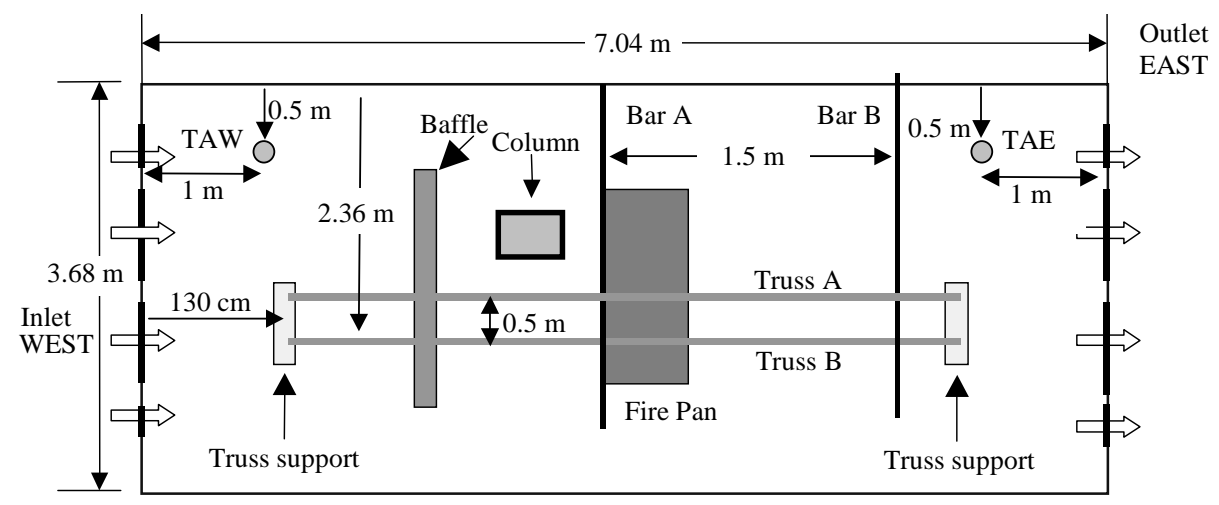

Fig. 1. Plan view of the experimental configuration.

Three types of steel components were selected for study: two bars, a hollow steel tubular column, and two bar-joist trusses. The bars were nominally $3 \mathrm{~m}$ long and $25 \mathrm{~mm}$ in diameter. The columns were $0.26 \mathrm{~m}$ by $0.36 \mathrm{~m}$ tubular steel sections with a nominal $6 \mathrm{~mm}$ wall thickness. The trusses were $4.6 \mathrm{~m}$ long and $0.8 \mathrm{~m}$ deep with $64 \mathrm{~mm}$ to $76 \mathrm{~mm}$ double angles for the top and bottom chords. The top and bottom chords of the truss were separated by $0.84 \mathrm{~m}$ and were bound by three web bars ( $25.6 \mathrm{~mm}$ thick) emanating from a single location on the bottom chord every $1.53 \mathrm{~m}$. The top surface of the truss chords was located $15 \mathrm{~cm}$ from the ceiling. Detailed drawings are given in Ref. [5]. The steel components were constructed of A572 steel, and the density was taken as $7860 \mathrm{~kg} / \mathrm{m}^{3}$; its specific heat was $450 \mathrm{~J} / \mathrm{kg} \cdot \mathrm{K}[6]$.

Bare-bead Type K 30-gauge thermocouples recorded the temperature histories at the steel surfaces. Thermocouple beads were spot welded to the bare steel surfaces. Each truss had thermocouples on its uppermost surface (denoted as TU-1, TU-2, TU-3, and TU-4) at $0.04 \mathrm{~m}, 0.19 \mathrm{~m}, 0.27 \mathrm{~m}$, and $0.42 \mathrm{~m}$ from the west end of the truss. Information on the exact locations of all of the compartment contents and instrumentation are described in Hamins et al. [5]. Measurements were made before the test began to obtain a baseline reference and after the fuel was stopped to observe cooling of the compartment and the steel elements. All of the data was acquired at a sampling rate of $1 \mathrm{~Hz}$.

\section{FIRE MODEL}

The compartment fire was modeled using the NIST Fire Dynamics Simulator (FDS) [7]. FDS was used to solve a low-Mach number form of the Navier-Stokes equations on a Cartesian grid using a large eddy simulation (LES) approach for turbulence. Combustion was computed using mixture fraction. Radiative heat transfer was computed using a finite volume method and the gray gas approximation. For further details, see Ref. [7].

Because the experiment was designed primarily to validate the model, the geometry and dimensions of the compartment conformed to a simple rectilinear grid. Although the CFD model is designed to predict the gas temperature, it also performs a simple one- 
dimensional calculation of the compartment walls and the steel as boundary conditions for the gas-phase.

The fire heat release rate and the yields of major combustion products were prescribed in the simulation. No attempt was made to model the spray burner, and the distribution of the heat release rate was assumed to be uniform over a $1 \mathrm{~m}$ by $1 \mathrm{~m}$ area in the fuel pan, which was consistent with observations of the hydrocarbon spray fire. A uniform numerical grid with cells $10 \mathrm{~cm}$ on a side was chosen based on a grid resolution study.

\section{FIRE-STRUCTURE INTERFACE}

This section describes the steps that are involved in transferring the results of the CFD fire simulation to a finite-element model of the thermal response of the steel members, referred to as the "Fire-Structure Interface" or FSI. The complete algorithm has been described in detail by Prasad and Baum [8,9].

A commercial software package, ANSYS 8.0 [10] was used to model the thermal response of the steel. First, finite-element models were developed for each structural component including the rods, the columns, and trusses. The solid models in ANSYS were meshed using the SOLID70 element for three-dimensional transient analysis. The SOLID70 finite-element has eight nodes with a single degree of freedom (temperature) at each node. Surface effect elements (SURF152) were used to model the convective and reradiative heat transfer to the structural elements. The surface elements were overlaid on the external faces of the structural components.

The next step was to predict the radiative and convective heat flux to the structural elements and to provide initial and boundary conditions for the three dimensional transient thermal calculation in the solid-phase. Calculating the radiation heat transfer between solid objects and the surrounding gases is difficult in large, geometrically complex buildings because of the wide disparity in length and time scales. A procedure for overcoming these difficulties was applied here. The large-scale temperature and other thermo-physical properties in the gas-phase were predicted using the CFD fire model. Four pieces of information were passed from the fire model to the thermal model. First, the gas temperature along a horizontal plane halfway down the height of the truss was saved in a text file, averaged over a time period of $30 \mathrm{~s}$. Second, the absorption coefficient along this same plane was also saved. Third, the depth of the smoke layer at each horizontal location was calculated using a simple integration of the vertical temperature profile. Finally, the temperature of the lower layer gases was represented by a horizontal slice in the first row of grid cells above the floor.

Two major simplifications were introduced to reduce the amount of information that needed to be passed from the fire model to the thermo-structural model. First, it was assumed that the hot, smoke-laden gas could be taken as "gray", that is, its properties were independent of spectral wavelength. Second, it was assumed that the enclosure geometry induced a vertically stratified distribution of temperature and combustion products. As the fire developed in the enclosure, the hot layer had spatial variations that changed much more rapidly in the vertical than in the horizontal direction. This assumption allowed the radiative transport equations to be simplified, and the radiative flux to any surface could be computed by solving a one-dimensional set of equations rather than three. The radiative flux to horizontal surfaces was obtained in terms of Exponential Integrals $E_{\mathrm{n}}(\mathrm{z})$, whereas that to vertical surfaces was obtained in terms of the $\mathrm{r}^{\text {th }}$ iterated integral of the Modified Bessel function, $K_{0}(\mathrm{z})$, as described in detail 
elsewhere $[8,9]$. Structural components in the hot upper layer and cooler lower layer were subject to convective fluxes with bulk temperatures values equal to the local instantaneous value of the temperature in the hot and cool layers, respectively. A convective heat transfer coefficient value of $25 \mathrm{~W} / \mathrm{m}^{2} \cdot \mathrm{K}$ was assumed [11].

The radiative and convective flux boundary conditions, as computed from the FSI plane layer analysis, were applied to the external faces of the structural components. Reradiation back to the ambient atmosphere was considered. The initial time step was set to $1.0 \mathrm{~s}$, while the minimum and maximum time step were set to $0.1 \mathrm{~s}$ and $20.0 \mathrm{~s}$ respectively. The FSI output was read into the ANSYS 8.0 [10] finite-element program to model the thermal response of the structural components. The uncertainty in the predicted thermal response of the structural steel components is discussed below in terms of model sensitivity.

\section{RESULTS}

\section{Comparison of Steel and Gas-phase Temperatures}

Figure 2 compares the temperature measured in the gas-phase using aspirated thermocouples located $17 \mathrm{~cm}$ below the ceiling with temperatures measured at four locations along the top surface of each of the two steel trusses, which were located $12 \mathrm{~cm}$ below the ceiling. The figure shows that the upper layer temperature on the East (outlet) and West (inlet) sides of the compartment were within $50^{\circ} \mathrm{C}$ of each other. The truss surface temperatures differed from the measured gas-phase temperatures in both absolute value and its time rate of change. The gas-phase temperatures heated and cooled more quickly as the fire was ignited and extinguished, respectively. The large time lags associated with changes in the steel temperatures were attributed to the relatively large mass and heat capacity of the steel trusses.

Figure 2 shows that there was a rather large range in the value of the temperature on the trusses (e.g., TU-1A and TU-3B). The steel surface temperature was as much as $250^{\circ} \mathrm{C}$ lower than the upper layer gas-phase temperature, or as much as $50^{\circ} \mathrm{C}$ higher, depending on the location, as seen in the measured profiles of the steel surface thermocouples. The results show that simple correlations based on averages of the upper layer temperature do not accurately describe the local thermal behavior of the trusses. The surface temperatures on the trusses were influenced by proximity to the fire, which controlled the magnitude of the local radiative and convective heat fluxes.

\section{Comparison of Fire Simulations with Measurements}

Figure 3 is a snapshot of a FDS simulation showing the isometric surface of stoichiometric mixture fraction to represent the fire, looking from the south toward the north wall of the compartment. The figure also shows the major geometric features of the compartment including the inlets, outlets, steel elements, and baffle. The simulation shows flames impinging on the steel truss, which is consistent with the video record [5]. Figure 4 compares the aspirated thermocouple measurements with the FDS simulated gas temperatures at three locations on the east side and three locations on the west side of the compartment (see TAE and TAW in Fig. 1). A portion of the aspirated thermocouple data was already presented in Fig. 2. The general trends in the measurements and predictions were in agreement. Quantitatively, the simulations typically under-predicted the hot gas layer temperature by anywhere from $1 \%$ to $10 \%$. Measurement uncertainty for the 
aspirated thermocouples was estimated as $7^{\circ} \mathrm{C}$ (or approximately $1.4 \%$ at $500^{\circ} \mathrm{C}$ ), which explains part of the difference between measurements and predictions. It should be noted that the pumps connected to the aspirated thermocouples did not begin to operate until roughly $200 \mathrm{~s}$ after ignition, so measurement results before that time are not presented. A comparison of measured and simulated $\mathrm{O}_{2}$ and $\mathrm{CO}_{2}$ volume fractions in the upper layer showed equally good agreement. The predicted $\mathrm{CO}$ volume fractions were not in agreement with the measurements due to the limitations of the mixture fraction model used in FDS for this species [5].

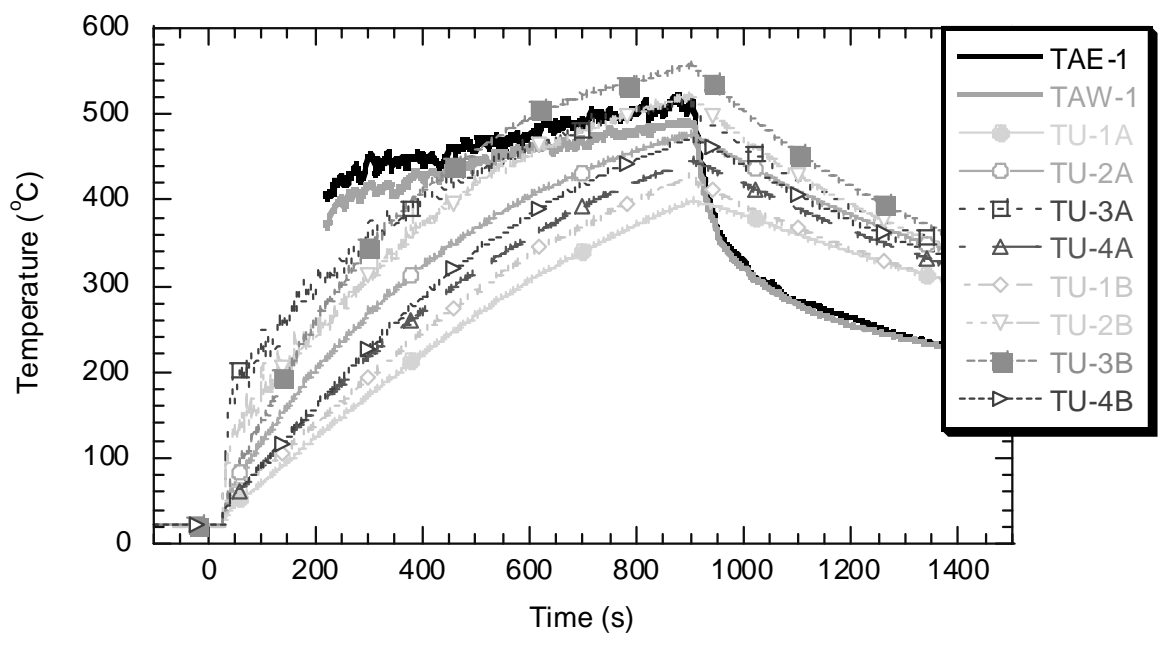

Fig. 2. The measured time varying gas-phase temperature $17 \mathrm{~cm}$ below the ceiling (365 $\mathrm{cm}$ above the floor) at the top East and West aspirated thermocouples

(TAE1 and TAW1, respectively) and at various locations on the top surface of Trusses A and B.

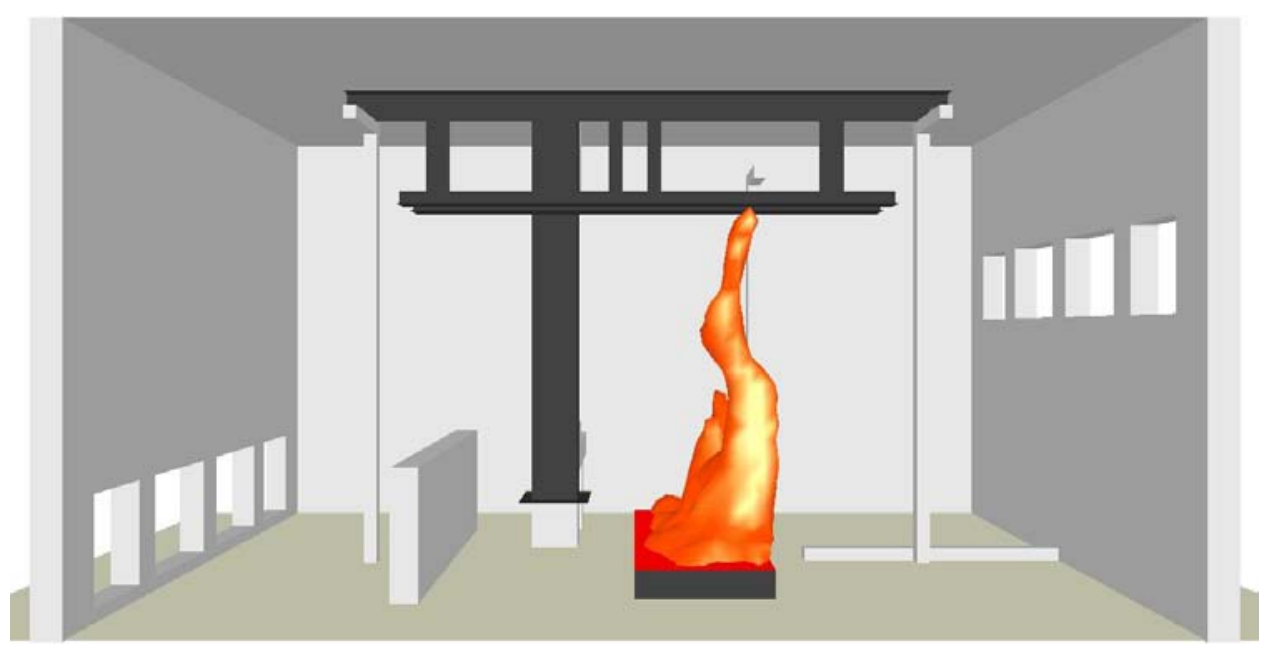

Fig. 3. Snapshot of the numerical simulation showing the fire as seen looking from the south towards the north wall. 

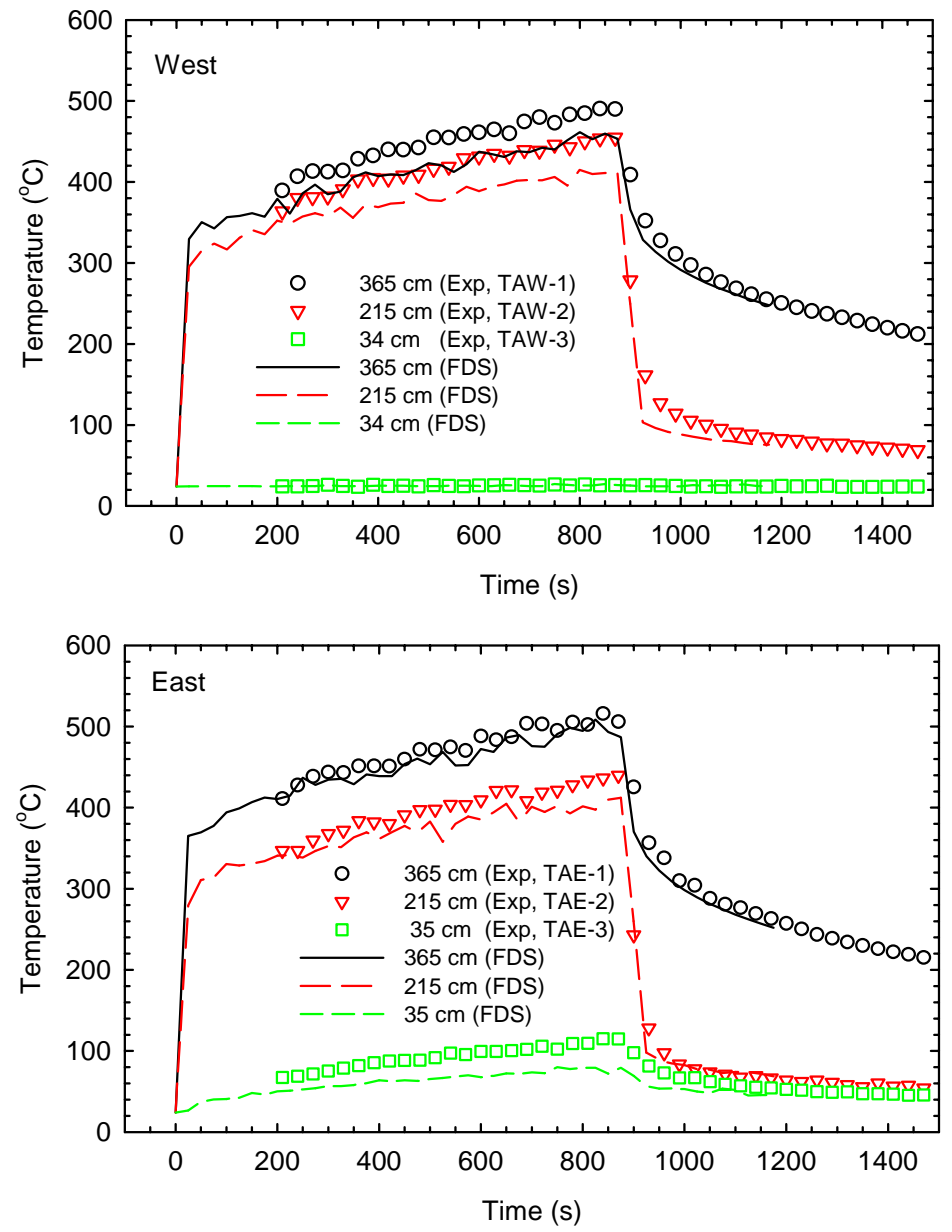

Fig.4. Comparison of the measured and simulated gas temperatures on the West and East sides of the compartment (TAE \& TAW) at 3 vertical locations $(365 \mathrm{~cm}, 215 \mathrm{~cm}, 35 \mathrm{~cm})$ above the floor.

\section{Comparison of Simulated and Measured Steel Temperatures}

Figure 5 compares the numerical simulations and the temperature measurements for various locations on the uppermost surface of the steel trusses. The plots show the results for various locations $3.70 \mathrm{~m}$ above the floor on Trusses A and B. The same steel surface thermocouple data are presented in Fig. 2. The numerical results match the trends of the measurement profiles reasonably well. For most locations, the maximum difference between the measurements and the simulations was less than $10 \%$. For a number of locations, the difference was as large as almost $30 \%$.

In terms of thermal load on a structural element, the maximum temperature is important. To determine the maximum possible temperature due to a fire that is spreading and moving, the temperature along the entire structural element must be considered. Consideration of the maximum temperatures that were reached at the hottest and coolest 
measurement stations on the steel elements during the experiment was used to summarize the agreement between the measurements and the simulations. The maximum temperatures on the steel occurred approximately when the fuel flow was stopped, which was at 860 s. This is seen, for example, in Fig. 5.
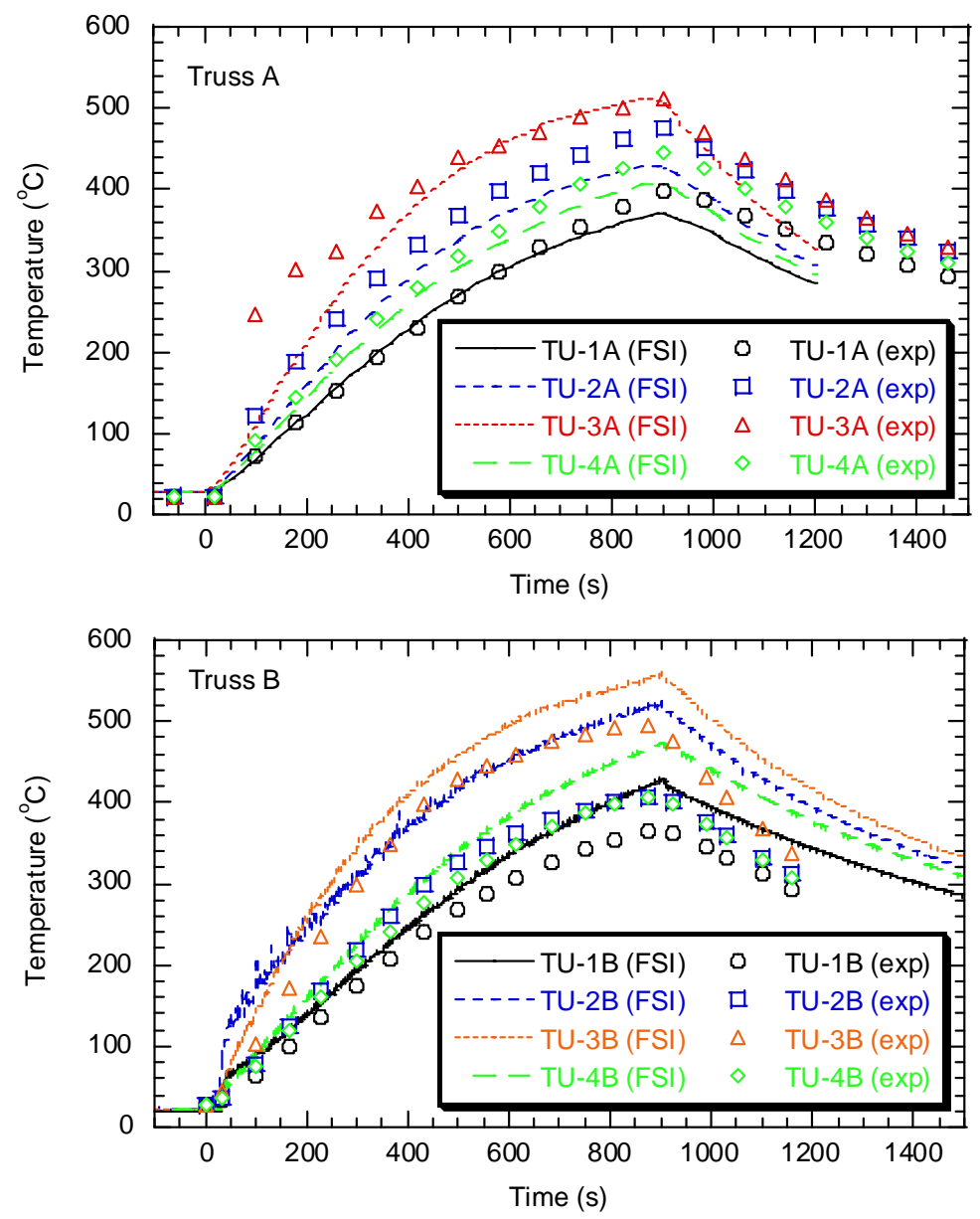

Fig. 5. Comparison of numerical simulations with measurements for the temperature at four locations on the top surface of Trusses A and B, $3.70 \mathrm{~m}$ above the floor.

The same steel surface thermocouple data are shown in Fig. 2.

The temperature measurements were also compared to the calculations at locations along the column, the rods, and at three heights above the floor on the trusses. The level of agreement between the calculated and the measured values of the peak temperature for the various steel components are summarized in Table 1 . The table lists the difference, for each location, between the peak values of the measured and the stimulated steel surface temperatures normalized by the average of those temperatures, with results listed for hottest and the coolest temperature locations on each element. A negative percentage in the tables indicates that the numerical simulation was less than the measured value, whereas a positive percentage indicates that the simulation was greater than the measured value. The average of the absolute values of the percentages is given at the bottom of 
each table and the average of the percentages are shown in parenthesis. The values were negative for all four cases, indicating that the numerical predictions consistently underpredicted the measurements by a finite, but small percentage. The average of the absolute value of the differences was less than $8 \%$, although some individual differences were as large as $12 \%$ to $15 \%$ for the hottest temperature locations, and as large as $10 \%$ to $20 \%$ for the coolest temperature locations on some of the elements. The uncertainty associated with a type $\mathrm{K}$ thermocouple measurement for near steady conditions is about $2^{\circ} \mathrm{C}$ [12]. Because the magnitude of the disagreement shown in Table 1 could not be explained solely by uncertainty in the measurement, further analysis was necessary.

Table 1. Percentage difference between peak values of the measured and simulated steel surface temperatures at the hottest and coolest locations on various uninsulated elements. The shaded entries were calculated with a heat release rate $10 \%$ higher than the baseline value.

\begin{tabular}{|l|c|c|c|c|}
\hline Element (Vertical Position) & $\begin{array}{c}\text { Hottest } \\
\text { Location }\end{array}$ & $\begin{array}{c}\text { Coolest } \\
\text { Location }\end{array}$ & $\begin{array}{c}\text { Hottest } \\
\text { Location }\end{array}$ & $\begin{array}{c}\text { Coolest } \\
\text { Location }\end{array}$ \\
\hline Bar A & $-10 \%$ & $3 \%$ & $5 \%$ & $5 \%$ \\
\hline Bar B & $8 \%$ & $-2 \%$ & $21 \%$ & $14 \%$ \\
\hline Column (2.13 m above floor) & $2 \%$ & $-2 \%$ & $-38 \%$ & $-26 \%$ \\
\hline Column (3.69 m above floor) & $-3 \%$ & $-6 \%$ & $-33 \%$ & $-22 \%$ \\
\hline Truss A (2.89 m above floor) & $-4 \%$ & $2 \%$ & $20 \%$ & $5 \%$ \\
\hline Truss A (3.29 m above floor) & $-6 \%$ & $-8 \%$ & $29 \%$ & $8 \%$ \\
\hline Truss A (3.70 m above floor) & $1 \%$ & $-10 \%$ & $4 \%$ & $4 \%$ \\
\hline Truss B (2.89 m above floor) & $-12 \%$ & $10 \%$ & - & - \\
\hline Truss B (3.29 m above floor) & $-15 \%$ & $-20 \%$ & - & - \\
\hline Truss B (3.70 m above floor) & $-6 \%$ & $-16 \%$ & - & - \\
\hline $\begin{array}{l}\text { Average of Absolute Values } \\
\text { (Average of Values) }\end{array}$ & $6.7 \%$ & $7.9 \%$ & $21 \%$ & $12 \%$ \\
$(-4.5 \%)$ & $(-5.1 \%)$ & $(1.1 \%)$ & $(-2.4 \%)$ \\
\hline
\end{tabular}

\section{Analysis of Experimental Uncertainty and Model Sensitivity}

The uncertainty in the predicted steel temperatures was related to the uncertainty in the gas temperature simulations, which in turn was related to the uncertainty in the heat release rate measurement. The local heat flux in the upper layer was dependent on the gas temperature, according to $q=\varepsilon \sigma T^{4}$, where $T$ is the gas temperature, $\sigma$ is the StefanBoltzmann constant $\left(5.67 \times 10^{-11} \mathrm{~kW} / \mathrm{m}^{2}-\mathrm{K}^{4}\right)$, and $\varepsilon$ is the emissivity of the gas. Whereas FDS predicted the upper layer temperature, in most cases, to within $10 \%$ of the measurements, even small inaccuracies could have been significant with a $T^{4}$ dependence.

Prediction of the compartment temperature depends on accurate prescription of the heat release rate $(\dot{Q})$ of the fire. According to an empirical correlation by McCaffrey, Quintiere and Harkleroad (denoted as $\mathrm{MQH}$ ), the rise in the upper layer gas temperature in a compartment is proportional to $\dot{Q}^{2 / 3}$ [13]. The reported expanded uncertainty in $\dot{Q}$ 
was $11 \%$, which corresponded to a $7.3 \%(=2 / 3 \times 11 \%)$ uncertainty in the temperature rise. For upper layer temperatures of approximately $500^{\circ} \mathrm{C}$, an $11 \%$ uncertainty in $\dot{Q}$ corresponded to a temperature uncertainty of $\pm 37^{\circ} \mathrm{C}$. The discrepancy between measurement and prediction for upper layer temperatures presented in Fig. 4, could be explained in terms of calculation sensitivity to uncertainty in the measurement of $\dot{Q}$.

A comparison of simulations with measurements showed that the heat flux onto solid surfaces in the upper layer was nearly given by $\sigma T^{4}$, where $T$ is the temperature in degrees $\mathrm{K}$. This implies that the emissivity of the upper layer gases was nearly 1 , not surprising given the high level of soot [5]. The upper layer temperature relative expanded uncertainty of $37 \mathrm{~K}$ represented a $5 \%$ uncertainty in absolute temperature, which led to an estimate for the uncertainty in the heat flux of: $4 \times 5 \%=20 \%$.

The shaded entries in Table 1 present the FSI predicted temperatures for the steel elements corresponding to a FDS simulation with the heat release rate $10 \%$ higher than the baseline value. The resulting simulated steel surface temperatures were $21 \%$ and $12 \%$ higher than the measurements at the hottest and coldest locations, respectively. The agreement with the measurements was either better or worse, depending on the element, and the particular location on the element. The sensitivity of the simulation results to variation of the heat release rate accounted for the range of differences between the measured and predicted steel temperatures.

\section{CONCLUSIONS}

A calculation of the temperatures of unloaded uninsulated steel elements subjected to a fire in a compartment was performed using a coupled procedure involving a CFD gasphase fire model, a finite-element model for the solid-phase, and a computation that served as an interface between the two. Measurements confirmed that simple rules of thumb to predict the thermal behavior of a structural element exposed to a fire do not hold. The interaction of the fire and the structure depends on details of the heat transfer processes at each particular location.

The simulations were in general agreement with the measurements. Both increased in a monotonic fashion from ambient values at ignition to finite values that obtained a maximum approximately when the fuel flow was stopped. On-average, the numerical predictions of the steel surface temperatures were within $8 \%$ of the measurements.

The differences could be attributed to model sensitivity to the heat release rate in the fire model. An $11 \%$ uncertainty in the heat release rate, led to a $7 \%$ uncertainty in the upper layer gas-phase temperatures and a $20 \%$ uncertainty in the heat flux to the solid-phase elements. The agreement between the measurement results and the simulations provides confidence in the application of this methodology for use in the performance-based design of conventional buildings in which a fire develops in a rectilinear compartment and a hot upper layer is created.

In actual buildings, structural steel members are not isolated. The presence of adjoining structural and non-structural building elements will affect the temperature profile of a structural steel member exposed to a fire. The methodology tested here would certainly be applicable in such cases. In addition, steel members in typical applications are often protected with fire protective insulation. The simulation of protected steel structures coated with fibrous insulation material was studied in a complementary set of 
experiments [5], which also considered a number of different fire heat release rates, fuel types, and steel insulation thicknesses.

\section{ACKNOWLEDGEMENTS}

The authors thank Lauren DeLauter, Edward Hnetovsky, Jack Lee, Jay McElroy, Roy McLane, and Mike Selepak for excellent technical assistance, and Drs. Rodney Bryant, Richard Gann, Thomas Ohlemiller, and Jiann Yang of NIST for very helpful discussions.

\section{REFERENCES}

[1] Lane, B., "A Performance Based Approach to the Design of Steel Structures in Fire," Proceedings of the International Conference on Engineered Fire Protection Design, 2001, pp. 415-426.

[2] Pchelintsev, A., Hasemi, T., Wakamatsu, T., and Yokobayashi, Y., "Experimental and Numerical Study on the Behavior of a Localized Steel Beam Under Ceiling Exposed to a Localized Fire,” Fire Safety Science -- Proceedings of the Fifth International Symposium, International Association for Fire Safety Science, 1997, pp. 1153-1164.

[3] Hamins, A., Maranghides, A., and Mulholland, G., "The Global Combustion Behavior of $1 \mathrm{MW}$ to 3 MW Hydrocarbon Spray Fires Burning in an Open Environment,” National Institute of Standards and Technology Report NISTIR 7013, Gaithersburg, MD, 2003, 15 p.

[4] Bryant, R., Ohlemiller, T., Johnsson, E., Hamins, A., Grove, B., Guthrie, W.F., Maringhides, A., and Mulholland, G., "The NIST 3 Megawatt Quantitative Heat Release Rate Facility - Procedures and Guidance," National Institute of Standards and Technology Special Publication SP 1007, Gaithersburg, MD, 2003, 81 p.

[5] Hamins, A., Maranghides, A., McGrattan, K., Ohlemiller, T., Yang, J., Donnelly, M., Mulholland, G., Prasad, K., Kukuck, S., and McAllister, T., "Federal Building and Fire Safety Investigation of the World Trade Center Disaster: Experiments and Thermal Modeling of Structural Steel Elements Exposed to A Fire,” National Institute of Standards and Technology Report NCSTAR 1-5B, Gaithersburg, MD, 2005.

[6] Banovic, S.W., McCowan, C., and Luecke, W., "Federal Building and Fire Safety Investigation of the World Trade Center Disaster: Physical Properties of Structural Steels," National Institute of Standards and Technology Report NCSTAR 1-3E, Gaithersburg, MD, 2005.

[7] McGrattan, K.B. (Ed.), "Fire Dynamics Simulator (Version 4), Technical Reference Guide," National Institute of Standards and Technology Special Publication SP 1018, Gaithersburg, MD, 2004, 94 p.

[8] Prasad, K., and Baum, H.R., "Coupled Fire Dynamics and Thermal Response of Complex Building Structures," Proceedings of the Combustion Institute, $\mathbf{3 0}$, pp. 2255-2262, (2005). 
[9] Prasad, K., and Baum, H., "Federal Building and Fire Safety Investigation of the World Trade Center Disaster: Fire Structure Interface,” National Institute of Standards and Technology Report NCSTAR 1-5G, Gaithersburg, MD, 2005.

[10] ANSYS, Inc., ANSYS Release 8.0 Documentation, 2003.

[11] Eurocode 4, "Design of Composite Steel and Concrete Structures, ENV 1993-12: General, EC4, Rules - Structural Fire Design,” European Committee for Standardization, Brussels, Belgium, 1994.

[12] Omega Engineering, Inc., Omega Temperature Handbook, Technical Reference Section, Section Z, 2000.

[13] Walton, W.D., and Thomas, P.H., "Estimating Temperatures in Compartment Fires," Fire Protection Handbook ( $3^{\text {rd }} E$ d.) DiNenno P.J. (ed.), National Fire Protection Association, Quincy, MA 02269, 2003. 